\title{
GENERAL APPROACHES TO THE FORMATION OF MODEL OF LOGISTICS OPERATORS IN SUPPLY CHAINS
}

\section{Saiensus Mariia ${ }^{1}$}

DOI: http://dx.doi.org/10.30525/978-9934-571-28-2_24

\begin{abstract}
The paper considers the theoretical and methodological foundations of the system organization of the functioning of logistics systems based on modern technologies. The results of the research presented in the work allow us to substantiate scientifically: measures to develop domestic logistics systems of companies to the level of $3 \mathrm{PL}$ and $4 \mathrm{PL}, 5 \mathrm{PL}$ - service providers; model management options for a company operating as part of a logistics chain; optimize the structure of the enterprise based on the goals and tasks in the field of logistics; to study the possibilities of introducing information technologies of fixing the company to the level of $3 \mathrm{PL}, 4 \mathrm{PL}$, 5PL - service providers.
\end{abstract}

For this purpose, the paper studies the theoretical foundations of the management of logistics systems by companies, based on the outsourcing of logistics and information technology level 3 PL and 4 PL, 5PL service providers. The subject of the study is the organization of the logistics systems of companies in the conditions of economic globalization.

The following research methods were used in the work: structural analysis, synthesis, comparison, economic and mathematical methods, research method related to target and synergetic principles, scientific methods and methodological apparatus of logistics management, the theory of material flow management of the methodology of economic efficiency evaluation of management and logistics technologies. The research was based on data obtained from the following sources of information: scientific publications and monographic publications of domestic and foreign scientists, materials of scientific conferences and studies, materials of periodicals, reports and analytical materials from official websites.

Recently there has arisen and is becoming more and more popular a new vision of acquisition of the logistics services - the so called 4PL model. The

${ }^{1}$ Candidate of Economic Sciences, Associate Professor,

Odessa National Economic University, Ukraine 
4PL model represents a further development of the 3PL-service providers, or Third Party Logistics, concept.

In the approach of a 4PL-service model, a logistics chain is a joint venture of a corporate customer and a logistic service provider that uses the 3PL procedures.

A 4PL provider is the only link between a customer and many 3PL providers. A 4PL provider becomes an integrator of a supply chain that joins its resources with those of its subcontractors. 4PL providers unite the possibilities of 3PL providers and companies managing the business processes in a manner that a customer receives all solutions related to organisation of a supply chain through a centralized contact management system using any managerial and information technology services.

Logistics supply chain development strategies are the basis for the development of the 5PL-service providers supplier as an independent, conceptually new and from all previous logistics operators, the highest level of outsourcing in the classification of the logistics operator.

\section{Introduction}

The overall trend of the logistics is linked to expansion of its functioning. The general framework of its activities is embracing more and more issues that were dealt with by separate companies and firms earlier. Such development determines creation by the very functions of logistics of its value added based on the systemic outsourcing.

This particular systemic character is due to the fact that certain clusters of companies' functioning converge on a common scheme organised on the specific-purpose and synergetic principles. The experience of the industrialised countries evidences that the systemic outsourcing is taking on greater and greater importance giving rise, in its turn, to an upgrowth of the value-added logistics.

\section{Formation of the problem}

Development of the conception of logistics outsourcing is driven by the trends of the economic globalization. Separate organisations become mainstreamed into the worldwide production network. The processes of supply and marketing become more complicated, too, and the level of logistics knowledge turns into the key factor of success for all the value chain partners. Consumers' increasing demand induces companies to 


\section{Saiensus Mariia}

apply such an instrument as outsourcing [10, p. 130-134] in their business activities.

The outsourcing of logistics functions lies in a transfer of any logistics functions (supply, production, sales) that may be fully or partially separate, and/or of any complex logistical business processes to an external outsourcer company.

All in all, it can be deduced that presently the definitions used in the field of outsourcing (in particular, the outsourcing of logistics functions), as well as the forms of interaction between any members of an outsourcing project have not been definitely established or accepted because partnering relationship within the framework of any particular outsourcing agreements can differ to a considerable extent. This is due to the rapid pace of development of this sector of business and the uprise of some new forms of relationship under the conditions of economic globalization and the legal restrictions imposed by some countries, etc.

\section{Description of the peculiarities of the concept "outsourcing of logistics functions"}

A Logistic Service Providers is a specialised commercial organisation carrying out some particular operations or complex logistics functions (warehousing, transportation, order management, physical distribution, etc.), as well as effecting an integrated supply chain management for its corporate customers.

A classification of logistic service providers including insourcing may be represented as follows:

1PL - First Party Logistics - refers to an autonomous logistics when an organisation performs a whole complex of logistical operations on its own;

2PL - Second Party Logistics - presupposes contraction of services of any monoline logistic service providers (such as carriers, forwarders, customs brokers, insurance companies, warehouses, and cargo terminals that perform separate logistics functions);

3PL - Third Party Logistics - means that all the logistics functions are outsourced to a logistic service provider that gives an all-around logistics support;

4PL - Fourth Party Logistics - is a logistic service provider performing a supply chain management (SCM) for a corporate customer; 


\section{General approaches to the formation of model of logistics operators...}

5PL - Fifth Party Logistics - means a "virtual logistic service provider" that assumes the functions of a 4PL applying at large the internet and any know-how as a single virtual platform ensuring a more profound and comprehensive interaction and coordination of work with the customers serviced.

In practice, the term "1PL" ("first party logistics") refers to any companies that specialise in some separate lines of activity in the field of logistics business. They focus on providing services in carrying out some separate operations upon delivery of cargo: transportation, storage, customs clearance, etc. As a rule, this segment of the logistics business is occupied by carriers, customs brokers, port authorities, stevedoring companies, transloading companies, etc.

Freight owners (both consignors and consignees) may enter into any contracts with any first party logistic company, whether directly or through any intermediaries which are usually determined in practical terms as 2PL-level providers representing the subsequent level of logistic services. Among companies providing services at the 2PL level are any forwarding, or freight forwarding companies that perform the role of intermediaries between buyers (freight owners) and sellers (1PL providers) of such services.

As opposed to the 1PL-type companies, the 2PL model implies providing complex services in several lines all at once. Thus, it can be illustrated with a situation when cargo is carried by several kinds of transport within a transportation system, customs clearance services being provided, as well. It should be mentioned that today such a business paradigm applied by the domestic forwarding companies is one of the most desirable.

Transition to a level of higher quality has resulted in origination of the term "a third party logistics", or "3PL", which refers to any outsourcer companies that sell an integrated service in delivery of cargo on the door-todoor principle accomplishing also all the operations required. Nevertheless, their functions exclude any management of freight traffic: in this case all issues will be assumed by a buyer, i.e. a consignor or consignee.

Depending on functions performed, all 3PL models are classified as:

1) standard (a standard service) ensuring performance of such functions as packaging, storage, and delivery of cargos;

2) service developer (an advanced service), which provides additional services in tracking cargos and transloading in case of an intermodal transportation; 


\section{Saiensus Mariia}

3) customer adapter (a service adapted to a consumer's needs), which provides complex services, mainly to small-business customers, in an efficient building of a logistic system, but does not develop any new kinds of services;

4) customer developer (an advanced service adapted to a consumer's needs) encompassing not only an external, but also internal logistics for a customer [1, p. 278-281].

Firms owning real assets own or acquire leasing vehicles, warehouses. Firms that use outsourcing services enter into agreements with other firms that provide all or part of the services in the field of physical distribution. Firms providing information services are a type of companies without physical assets that act as intermediaries in optimizing the logistics systems of enterprises and interact with other asset-owning firms on a contract basis.

A 3PL model implies a whole complex of logistics services, from delivery and cell-based storage to order management and goods tracking. A 3PL provider's functions include organisation and management of cargo shipping, stock record and management, preparation of import and export documents, warehouse storage, cargo handling, and delivery of an ultimate consumer.

Turning to the experience of the Western market, it is possible to note the key problems arising in the interaction with 3PL-providers or are constraining factors for such interaction. The first is the unrealized conditions fixed in the SLA, and the absence of the expected cost optimization (Table 1, Table 2).

The task of management of many companies as a single system in logistics should be understood, first of all, as a service for supply chain partners. In theory, there is a settled notion "a fourth-level logistic service provider", similarly to and as extension of the notion "a third-level logistic service provider". When a customer deals with a logistic service provider of this type, the former may rely on a comprehensive service and assistance with an adaptation to the ever-changing conditions of the external situation, which is an additional factor for an enhancement of such a logistic service provider's competitiveness. However, a provider of the 3PL generation does not solve any problems related to freight traffic: this function is still performed by a freight owner.

Therefore, appearance of a 4PL provider on the market of logistics services can be qualified as expected and foreseeable. The term "4PL" was registered for the first time by a consulting company styled Andersen Consulting, now renamed Accenture, in 1996, as having the meaning as follows: "A fourth-level logistic service provider is a supply chain manager 
General approaches to the formation of model of logistics operators...

Table 1

Problems faced by companies, referring to the 3PL-provider, \%

\begin{tabular}{|c|l|c|c|c|}
\hline №№ & \multicolumn{1}{|c|}{ Problems with 3PL Providers } & Europe & America & Asia \\
\hline 1. & Unrealized agreements and services agreements & 46 & 43 & 46 \\
\hline 2. & $\begin{array}{l}\text { The shortage of long-term, constant improvements } \\
\text { and achievements in the proposals }\end{array}$ & 41 & 37 & 41 \\
\hline 3. & Cost reductions have not been achieved & 37 & 37 & 34 \\
\hline 4. & Unsatisfactory IT services capabilities & 31 & 38 & 38 \\
\hline 5. & Lack of experience in project management & 35 & 31 & 36 \\
\hline 6. & $\begin{array}{l}\text { Unsatisfactory transition period in the process of } \\
\text { implementation }\end{array}$ & 28 & 34 & 33 \\
\hline 7. & $\begin{array}{l}\text { Ineffective management of key performance } \\
\text { indicators }\end{array}$ & 27 & 28 & 31 \\
\hline 8. & Too many problems related to the human factor & 28 & 30 & 32 \\
\hline 9. & Lack of consulting, intellectual skills & 23 & 22 & 34 \\
\hline 10. & Impossibility of providing services on a global scale & 19 & 16 & 20 \\
\hline 11. & $\begin{array}{l}\text { Insufficient integration of business processes across } \\
\text { regions and across the supply chain }\end{array}$ & 18 & 21 & 28 \\
\hline 12. & Inability to build a purposeful and reliable relationship & 13 & 15 & 19 \\
\hline 13. & $\begin{array}{l}\text { Weak information integration with the acquired } \\
\text { companies }\end{array}$ & 13 & 12 & 21 \\
\hline 14. & Lack of problems & 16 & 17 & 5 \\
\hline
\end{tabular}

Source: the table was compiled by the author on the material [11]

Table 2

Reasons why companies do not address the services of 3PL operators (\%)

\begin{tabular}{|c|l|c|c|c|}
\hline №№ & \multicolumn{1}{|c|}{ Reasons } & Europe & America & Asia \\
\hline 1. & Logistics is a key activity of our company & 28 & 34 & 26 \\
\hline 2. & Abbreviations costs are not expected & 44 & 39 & 36 \\
\hline 3. & Level of service agreements will not be implemented & 28 & 34 & 32 \\
\hline 4. & Logistics is too important to outsource & 30 & 30 & 24 \\
\hline 5. & Decrease in control over outsourced functions & 23 & 32 & 8 \\
\hline 6. & Better practice than most 3PL operators & 26 & 23 & 12 \\
\hline 7. & Corporate ideology excludes access to 3PL operators & 16 & 11 & 20 \\
\hline 8. & $\begin{array}{l}\text { Need to improve the capabilities of 3PL operators } \\
\text { globally }\end{array}$ & 23 & 16 & 8 \\
\hline 9. & $\begin{array}{l}\text { Security-related issues transportation and shipment } \\
\text { of goods }\end{array}$ & 7 & 18 & 20 \\
\hline 10. & $\begin{array}{l}\text { The inability of 3PL providers to build a focused and } \\
\text { trusting relationship }\end{array}$ & 14 & 14 & 8 \\
\hline
\end{tabular}

Source: the table was compiled by the author on the material [11] 


\section{Saiensus Mariia}

that brings together its own resources, capabilities, and technology with the resources, capabilities, and technology of another logistics service provider and manages the same in order to offer a solution of tasks in a supply chain to its customers to the fullest possible extent" [1, p. 197].

It is important that all the 4PL providers, or fourth-level providers, be by all means involved in a manufacturing process. As a rule, a 4PL provider is a major logistics service provider having a large infrastructure and advanced supply chain management systems and accomplishing high-technology processes and complicated logistic schemes.

In order to achieve the level of a 4PL provider, there are possible ways as follows: a third-level logistic service provider may develop until the level of a 4PL one. A manufacturer of an ultimate product may organise a business on the principle of a 4PL model for solution of any similar tasks. A consulting company may assume the role of a $4 \mathrm{PL}$ provider. A company engaged in providing services in the field of IT may become a 4PL provider. A supply chain partner may become a 4PL provider.

The evolution of a third-level logistic service provider seems the most appropriate. Given the business contacts with customers established by a company, it will be the most likely. Parallel to planning of their own routes, these companies shall fulfil such tasks as planning of coordination of transport, warehouse and stock management for their customers, as well as shall render any other services implying emergence of a value added.

Nevertheless, there may arise some problems with customers, who can misunderstand the new role of such a company:

- on the one part, a consignor may be doubtful of impartiality of a logistic company ;

- on the other part, today the information technology structure of many potential 3PL logistic providers only reflects the needs of a logistic company itself, but does not allow effecting the overall management, even if there are appropriate interfaces, that may function perfectly well, for exchange of data with customers and subcontractors.

\section{Variants of achievement 4PL - Fourth Party Logistics}

Let us consider some variants:

Variant "Transportation Provider". A transportation service of the manufacturers of an ultimate product (a holding company) that was rendering cartage services earlier will turn into a 4PL provider. 


\section{General approaches to the formation of model of logistics operators...}

A goods manufacturer, being usually a holding company or a transnational corporation (TNC) or a financial industrial group (FIG), shall found a subsidiary transportation company as a 4PL-level provider. They will implement a partial strategic and day-to-day management for their parent company and, in some cases, will assume in full all the logistic processes related to supply and marketing.

They will also organise a horizontal and vertical structure of the system optimising constantly the processes, providing their information technology structures for carrying out any processes to be implemented, and integrating partially the IT systems of their parent company and those of their previous and subsequent supply chain partners. However, since the management systems of a parent company dominate the systems of any similar logistic service provider, an all-round optimisation of the supply chain seems hard to be achieved.

Variant "Consulting Company". Another opportunity for a start-up of a 4PL provider is there when the tasks related to management and coordination are committed to a consulting company. In many instances, such companies are actively involved in creation of a strategic configuration of a supply chain and provide backstopping upon deployment and operation of the software for SCM.

Besides, consulting companies usually have a proper competence in holding tenders and issuing orders for logistics services for any 3PL and 4PL providers. Commonly, similar tasks form part of a standard service package offered by a consulting firm. Large consulting companies, however, that are engaged in the field of strategic research often become knowledgeable of a whole supply chain, but have little understanding of the business processes. Therefore, only such consulting companies that advise their customers at the level of logistics business processes and manage all the internal processes by means of their own interfaces are in a position to organise management of a whole supply chain. To this extent, they should be involved in development of a strategic vision by their parent company.

Variant "IT Providers". Software manufacturers and IT providers also stand a chance of becoming a 4PL provider. Supply chain management very often requires specific software with an enormous number of interfaces to integrate the enterprise resource planning systems belonging to supply chain partners. Any know-how in the field of information technologies becomes all the more important for a successful supply chain management. 


\section{Saiensus Mariia}

Therefore, IT providers seem to have the best background to solve any and all issues including the functioning of e-commerce, through a supply chain portal. This portal is intended to connect all the partners through the Internet in order to implement any physical processes, which also implies the integration of logistic service providers. Such a portal can also ensure the transparency in the network which is necessary for an optimum supply chain.

Variant "Synthesis". This variant implies that a parent company takes over some lines of business activities that already form part of an existing supply chain. It means that some joint ventures may be organised, whether on the basis of any IT firms or any consulting companies and third-level logistic service providers. In this case, the independence of a subsidiary company from its parent one in respect of any specific plans involving its participation in a supply chain and a possibility to avoid any conflict of interests takes shape as the vital task.

\section{Modeling features 5PL - Fifth Party Logistics}

In the modern educational and scientific-methodical literature, many authors distinguish 5PL logistics providers (Fifth Party Logistics) as a separate element in the classification of logistics operators $[1 ; 2 ; 8 ; 10]$. Under the 5PL, a provider is generally understood to be a logistics operator whose activities are based on the use of a complex of modern information and communication technologies that allow the database of consignors, consignees and transport companies to be interactively operated, plan transportation, dispatch and monitor the execution of orders in a virtual logistics system $[1 ; 9 ; 10]$. Many authors, and in particular A.V. Ivashchenko and D.G. Peysahovich, is understood by the operator's 5PL provider, which basically manages the flow of information about orders, resources, plans and the actual state of the transport network in the integrated supply chain [7, p. 153-158].

If we consider 5PL providers from the point of view of the integration approach, as do Loshnev K.O., Taraskina E.P., Zarudnev D.I., Dikinov A.H., Honchukaeva L.V. and Aitbagin E.R., then under 5PL-provider it is necessary to understand management of all components of the integrated supply chain, and not only information flows. Such management is understood within the framework of a single information space, using the Internet as a unifying virtual platform $[10$, p. 320]. Such a system is also called "virtual logistics" or "Internet logistics" $[1 ; 2 ; 4 ; 6 ; 10]$. 


\section{General approaches to the formation of model of logistics operators...}

In this case, the 5PL provider is already defined as a "service company that performs integrated services for managing integrated processes in supply chains on the basis of outsourcing without the use of physical mechanisms for managing material and other logistical flows" [11, p. 70-72].

According to Aitbagina E.R. The 5PL provider is a logistic operator that takes over the functions of the 4 PL operator and provides deeper and more comprehensive interaction and coordination of the clients' services in real time with extensive use of the Internet [3, p. 14-17]. However, this interpretation of the 5PL provider also does not make it possible to separate it as a separate, independent element of the classification of logistic operators.

This seems impossible in view of the fact that according to the experience of practitioners themselves, 3PL - and 4PL-providers themselves several years ago already switched to maximizing the full informatization and virtualization of their activity and without giving up their material and technical base, but, on the contrary, strengthening it and automating it.

Virtualization, informatization and automation of 3PL and 4PL providers has become a routine and necessary practice of the modern market today and does not cause a significant expansion or radical change in the range of logistics services providers, goals and processes of their services, therefore, does not change their species, process or functional composition and does not allow to allocate such kind of "virtual" or "Internet providers" as a new type of logistic operators.

This is also confirmed by the words of Cedric Alambert that the features of Internet commerce and Internet logistics today are mostly related to the positioning of products and services, but business-logistics technologies, developed with traditional formats of sales, largely in e-commerce are simply repeated $[2$, p. 16]. This point of view was first substantiated by Professor Sergeev V.I. in the textbook on supply chain management $[5 ; 10$, p. 120]. He notes that changes related to the development of the Internet and electronic business have a strong impact on various segments of the logistics services market, which as a whole develop integratively.

However, e-commerce is not a new segment or a new criterion for classifying supply chain management solutions. It leads only to the formation of a wider range of offers of integrated services 3PL- and 4PL level in supply chains [10, p. 261].

The emergence of this concept is primarily due to the fact that the rapid development of modern information systems and technologies makes it 


\section{Saiensus Mariia}

possible to introduce the most powerful and progressive technologies into the sphere of economy, business and logistics service, providing an unprecedented, previously impossible level and scale of data processing that forms the basis To make decisions not only operational level, but also strategic.

These technologies include not only embedded in the field of logistics outsourcing Internet technologies and electronic document management technologies. Changes in strategic logistics planning are primarily related to the introduction of intelligent systems based on neuro-cybernetic data analysis technologies, as well as expert technologies of automated machine management decision-making and impact on subordinate objects.

However, one can add to this that the development of expert systems and neurocybernetics, as well as the ever wider and more active use of cloud computing, distributed computing, remote and distributed databases, will allow the transition to a fundamentally new level of information processing and decision making, consisting in their automation and implementation without any permanent human intervention [8, p. 54-56].

Technologies of distributed computing will allow processing practically unlimited volumes of information and, consequently, serve logistic chains and logistic networks of any scale, both national, international, and planetary.

This will allow us to cover and integrate logistics networks and supply chains in each country, economic or geographical alliance, as well as on different continents, in the future creating and servicing a single global economic-distributive network of commodity economy. In turn, artificial intelligence technologies will automate the decision-making process in logistics networks of this scale, replacing in this issue the intellectual abilities of a person who in this case will not be physically able to cope with the scale of such activities.

Modern reality can be absolute impartiality and maximum optimality from the point of view of the effectiveness of the functioning of the entire logistics network, the life activity of states and economic unions. The society will be able to approach the optimal food and commodity supply of the national economy and consumer, environmental and energy security and economy. The use of artificial intelligence technologies will solve the problems and eliminate the bottlenecks associated with the issues of interorganizational logistics coordination in supply chain chains and networks arising from the opposite of the interests of the network participants, and will also 
allow not only the most effective operational accounting, control and planning of the logistics networks, but also to carry out tactical and strategic management of logistics networks based on self-learning expert systems.

At the present stage, the 5PL -provider has the opportunity to move from the ordinary link of the logistics supply chain, performing for it a certain list of logistics functions, to a full-fledged entity managing logistics chains and supply chains [10], to the subject of political and economic management. At this stage, its process and functional composition is changing, the range of services and goals is expanding and drastically changing.

The 5PL provider begins to determine the policy of development of the global logistics service, and, consequently, the policy of economic development. With the use of these technologies, the 5PL provider has the opportunity to set the system of co-ordinates of activities for the participants of logistics chains and supply networks, act as an integrating factor, and find a very mobile and constantly changing balance between the multidirectional interests of states, consumers and commercial participants of logistics networks of food and industrial goods.

And, it can be concluded that in this context it is the conceptual changes in the goals, tasks, functions and scope of activity, as well as the place, role and purpose of the logistics provider in the supply chains that allow us to talk about a really new step and a new level in the classification of logistics operators.

It is the enumerated possibilities of independent determination of the strategy for the development of logistics chains and supply chains based on a given, chosen political concept and automated compulsion of the participants in the supply chain to execute it, are the basis for distinguishing the 5PL provider as an independent, truly conceptually new and fundamentally different from all previous logistics operators, the provider of the highest level in the classification of operators of logistics outsourcing.

A logistic intermediary represents an essential element in a logistic service provider company because the cooperation with the former allows a company to get any competitive advantage for account of:

- a reduction in operational logistics costs, overall increase in efficiency of the functioning of a logistics system and, as a consequence, reduction in prime cost of goods;

- enhancement of flexibility and adaptation of a company to the ever-changing environment; 


\section{Saiensus Mariia}

- mitigation in logistics risks; reduction in duration of the operational and logistics cycles.

Whereas previously the field of logistics represented, at the most, the classical kinds of logistical services, such as stockpiling, transportation, and cargo handling which take shape as a particular physical operation, now the logistic activities are deemed to include any coherent business processes having a coordinating and strategic nature.

All logistic service providers are divided into classes reasoning from the nature of their activities; it may be operating, coordinating or strategic:

- monoline logistic intermediaries (transportation companies, forwarding agents, jointly occupied depots, cargo terminals, customs brokers, agents, stevedoring companies, insurance companies, providers of any information and consulting services in the field of logistics);

- 3PL providers, which embrace any firms rendering a coherent logistics service for a customer (being a manufacturing company, commercial partnership or a service provider);

- 4PL providers representing any systems logistics integrators.

Monoline logistics intermediaries focus on the operating activities. A 3PL providers carry on the operating and partially coordinating activities (which means integration and coordination of the operating functions in a single provider). A 4PL providers tackle the coordination and strategic activities (which presupposes a systematic approach to the management of any core logistics business processes, integration and coordination of actions undertaken by a target company and key contracting parties in a supply chain).

At present, transportation companies often take on lease or build their own distribution centres, warehouse operators include any transportation departments in their infrastructure, and customs brokers and forwarders offer services in delivery, storage, and batching of the flows of goods.

Modern 3PL providers have traversed the course of a synergetic amalgamation of some specific services. 3PL service represents a multidisciplinary adviser offering and implementing appropriate solutions for the supply chain management. Major companies having large turnovers and flows of goods purport to obtain the necessary services from a single provider.

The development of a 3PL model has led to the next step - emergence of the 4PL services. 4PL provider addresses the tasks related to a strategic planning, management and control of all the logistics processes of a corporate customer. 


\section{General approaches to the formation of model of logistics operators...}

\section{Creation of a common information space}

for expansion of the outsourcing of logistics functions

Creation of a common information space as an environment for an integrated planning and management of any supply chain interactions and as a tool for perfection of a supply chain management system is fundamental for expansion of the outsourcing of logistics functions. The crucial factor determining the prospects and opportunities a company has in order to develop its models of integrated planning and management of its supply chains on the basis of the outsourcing of logistics functions is the state of the information technologies.

The main objective of managing logistic communications is to provide a favorable attitude to the manufacturer of goods by creating a common motivational field of exchange participants which is focused on the rational use of available resources and harmonization the interests of the parties. The modern concept of logistic communications is the concept of integrated logistic communications, actively explored and developed today by the researchers of the problems of interaction of subjects in the logistic.

Methodological weakness of the concept of integrated logistic communications is that it implies the implementation of integration only on instrumentality level, regardless of the set of participants in the interaction and their characteristics (motivation, resource, organizational, technical, innovation, etc.). Depending on our opinion, integration should have a response in the form of conjugation motives of participants, their resources, actions logisticing in satisfaction the needs of consumers differ in their behavior under various conditions of logistic conditions and the particular communication area.

The concept of integrated logistic communications, which provides large-scale use of low-budget tools logisting communications, should be transformed into the concept of the integrated logisticing communications [1, p. 134-145]. The last implies the creation and development conducive for the initiator communicative environment providing modification of consumer perceptions and behavior of target groups and to achieve the strategic goals of the enterprise.

The main objective of managing logisticing communications is to provide a favorable attitude to the manufacturer of goods by creating a common motivational field of exchange participants which is focused on the rational use of available resources and harmonization the interests of the parties. 


\section{Saiensus Mariia}

The objectives of the management of logisticing communications in the context of disclosure of key management components by the manufacturer of the goods (its philosophy, mission, vision, features subculture, image, reputation) may include the following:

- determining the level of permeability of logisticing actions;

- monitoring of "susceptibility" logisticing efforts with regard to the promotion of products by manufacturer; adjustment of properties and characteristics of integrated communication cycle.

The solution of the challenges in business requires effective management of increasingly complex system of logisticing communications, supporting mutually beneficial exchanges between suppliers, intermediaries, customers and various contact audiences.

When the business rises the manufacturer expands the circle of perspective for him the participants of logisticing process, thereby expanding the scope of the entire interaction. In front of a enterprise there is the task of forming its logisticing communications field in the sense in which we have identified and marked economic nature of communication.

This consequence requires consideration of communication tools, determining the boundaries of their applicability and systematization of different scientific approaches to the study of proper communication as the essential foundation for an effective interaction. Introduced new concepts to a better understanding of the components of the communication area, and on this basis provide a framework for consumer benefit and achieve satisfaction exchanges through intensified logisticing process. Achievement the satisfaction with the exchange interaction between the participants can only be achieved in a single motivational field, which established a balance of interests in respect of resources defined by the level of profitability and the desired values of the created product that can satisfy the needs of the target customer segments.

Corporate of logisticing takes the form of an open logistic for dialogue partnership; innovation does not reject the action as a complex resource factor for competitiveness entities increasing in the process of establishing constructive communication between them. The mechanism of interaction management links the determining factors in the context of a single communication cycle, a custom adaptation of business structures to logistic requirements [1, p. 78-82].

Changing the amount and composition of logisticing communications, and an array of quality broadcast through them information, we proposed 
a mechanism for adjusting the behavior of consumers in the direction favorable to the enterprise. As part of the anthropocentric approach cognitive dimension of consumer behavior acquires the properties of instrumental function.

Priority is given to understanding rather than explanation or prediction. Under the influence of factors of different orders it generates a set of alternatives to buying. Mass logisticing is targeting producers to logistic segments, taking into account the profile of the user and their responses to the impact of the enterprise.

Personalization of communications by the company assumes knowledge of consumer reaction and adequate assessment of the proposed values. The company creates the conditions for access to the individual through the activation of the tools of logisticing communications. At the same time, the company is building its information field through memorization of response of the consumer and stores this information in one of its subsystems [1, p. 22-28]. Differentiation of target groups of consumers on the factor "type of competitive behavior" [10] makes it necessary to differentiate the content and logisticing channels broadcast information aimed at consumers (modification of consumer perceptions and behavior) and logistic agents (modification of the Counterparty on the activities of the enterprise). Simulation of communication processes is developing mainly representatives of social and humanitarian sciences and engineering in the direction of building models on the basis of analogy, while the area of economic and mathematical modeling remains largely unexplored. Offer relevant solutions in this field allows you to expand the scientific tools in the management of the enterprise communication, increase its precision and focus, identify typical application situation of communication tools in competitive strategy and conduct scenario of economic-mathematical calculations to assess the feasibility and effectiveness of the investment of resources in the communicative sphere of business.

Management of many companies as a single system requires: introduction of a common management platform; determination of all tasks, rights, and duties to be vested in a single management towards any supply chain partners that are legally and financially independent businesses. Companies owning real assets possess or acquire, by way of hire purchase leasing, any vehicles, warehouses, etc. 


\section{Saiensus Mariia}

Those companies that contract the outsourcing services enter into agreements with any other providers of services, whether in a full or partial scope, in the field of physical distribution. Firms rendering any information services represent a type of companies not having any physical assets and carrying on the business of intermediaries in optimisation of the logistical systems of any other companies and interacting with any other firms or companies that have real assets, on a contractual basis. The criterion of segmentation of the market, the so called logistics assets, does not exclude the third variant, either: one's own logistics capacities and outsourcing. In this context, depending on the actual conditions of a company's business activity on the market of logistics services, it is not always possible to put into operation all the logistics capacities.

\section{Conclusion}

1. Logistic outsourcing is a consequence of the evolution of a modern enterprise. The change in general methodological approaches to the organization of the production process, systems and management process is associated with such factors as: greating an internal competitive environment; transition from functional to technological specialization; reengineering of production processes; changing the system of internal and external communications; intensification of information exchange; striving to reduce costs. The methodology of logistics outsourcing develops and is reflected in all modern types of organizational structures.

2. The structure of the process of logistics outsourcing presupposes a strategic and economic justification for the need to delegate authority for certain processes and activities. The choice of the provider of logistics outsourcing services is carried out as a result of the analysis of the available services market.

3. Modeling the process of logistics outsourcing requires the formalization of socio-economic factors that influence the decision on logistics outsourcing. Modeling the process of logistics outsourcing allows to formulate a general methodical approach to making managerial decisions about the use of certain types of outsourcing.

4. There has arisen and is becoming more and more popular a new vision of acquisition of the logistics services - the so called 4PL (Forth Party Logistics) model.

5. The 4PL model represents a further development of the 3PL, or Third Party Logistics, concept. In the approach of a 4PL model, a logistics chain 
is a joint venture of a corporate customer and a logistic service provider that uses the 3PL procedures.

6. 4PL provider is the only link between a customer and many 3PL providers. A 4PL provider becomes an integrator of a supply chain that joins its resources with those of its subcontractors. 4PL providers unite the possibilities of 3PL providers and companies managing the business processes in a manner that a customer receives all solutions related to organisation of a supply chain through a centralized contact management system using any managerial and information technology services.

7. It is these listed opportunities for independent determination of the logistics supply chain development strategy that are the basis for allocating the 5PL provider as an independent, truly conceptually new and fundamentally different from all previous logistics operators, the highest level provider in the classification of logistics outsourcing operator.

\section{References:}

1. Anikin, B. A., Rudaya I. L. (2009) Autsorsing $i$ autstaffing: vysokie tekhnologii menedzhmenta [Outsourcing and outstaffing: high technology management]. Moscow: INFRA-M. (in Russian)

2. Amblar S. (2016) Dlya uspekha biznesa e-commerce neobkhodim edinyy provayder [For the success of e-commerce business, a single provider is needed]. Logistika. No. 2, pp. 14-17.

3. Aytbagina E.R. (2016) Rol' logisticheskikh posrednikov i provayderov (operatorov) [The role of logistics intermediaries and providers (operators)]. Engineering and technology of construction, vol. 2, no. 6, pp. 2-3.

4. Baginova, V. V., Kuz'min D. V. (2013) Osobennosti razvitiya kontreylernykh perevozok v Rossii [Peculiarities of the development of piggyback traffic in Russia]. Modern problems of the transport complex in Russia, vol. 4, no 4, pp. $49-52$.

5. Dybskaya V.V., Zaytsev E.I., Sergeev V.I., Sterligova A.N. (2013) Logistika. Polnyy kurs MVA [Logistics. Full MBA course]. Moscow: Eksmo. (in Russian)

6. Dikinov A.Kh., Khonchukaeva L.V. (2014) Problemy razvitiya logisticheskogo autsorsinga $\mathrm{v}$ Rossiyskoy Federatsii [Poblems of development of logistics outsourcing in the Russian Federation] Bulletin of the Mordovian University, vol. 24, no 4, pp. 94-102.

7. Ivashchenko A.V., Peysakhovich D.G. (2013) Pro aktivnaya dispetcherizatsiya resursov transportnogo operatora 5RL [Proactive dispatching of transport operator resources 5PL] Intelligence. Innovation. Investments, no 3, pp. $153-158$.

8. Kuramshin N.D. (2016) 5PL - novyy uroven' logisticheskogo autsorsinga [5PL - a new level of logistics outsourcing]. Successes of modern science and education, vol. 3 , no. 8 , pp. 54-56. 


\section{Saiensus Mariia}

9. Lishnev K.O. (2012) 5PL-provaydery kak perspektivnyy etap razvitiya logisticheskogo autsorsinga [5PL-providers as a promising stage in the development of logistics outsourcing]. Proceedings of the Materials of the International Interuniversity Scientific Master Conference: a collection of reports. Under the ed.: T.I. Tumarova, I.N. Samonova, N.S. Slavetskaya. Collection: Russia in the modern world: in search of an innovative strategy; new growth models. (Russia, Nizhny Novgorod, March 20-23, 2012), pp. 244-246.

10. Sergeev V.I. (2015) Upravlenie tsepyami postavok: uchebnik dlya bakalavrov $i$ magistrov [Supply Chain Management: A Textbook for Bachelors and Masters]. Moscow: Yurayt (in Russian)

11. Tityukhin N. (2007) Byt' li v Rossii 4PL provayderam : tendentsii logisticheskogo rynka [Do 4PL providers in Russia: trends in the logistics market?] Loginfo, no. 12 , pp. $20-28$. 